\title{
Desenvolvimento de Sistema de Recepção com Amplificação do Nível de Sinal Digital de Alta Definição
}

\author{
Diego de Moura, Ingrid C. Cezário, Adroaldo Raizer \\ Universidade Federal de Santa Catarina \\ Florianópolis, Brasil.
}

\begin{abstract}
This paper presents the development of an a radiofrequency amplifier based on a transistor that operates at high frequency. In order of determining the increase of the signal level via amplification, a half-wave dipole antenna $(\lambda / 2)$ with geometry inspired by the meander line antenna type (MLA) also is developed. Simulations using software based on the finite element method were performed and the antenna reception efficiency was evaluated through measurements.
\end{abstract}

Index Terms - Antenna Development, meander line antenna (MLA), HDTV, a radio-frequency amplifier.

\section{INTRODUÇÃO}

$\mathrm{C}$ OM o crescimento progressivo e contínuo da oferta de serviços de comunicações sem fio, tem sido cada vez maior a busca por dispositivos que operem de forma eficiente em diferentes faixas de frequência, atendendo às características requeridas como largura de banda e bons níveis de sinais.

Nesta perspectiva, destaca-se a televisão digital de alta definição (HDTV), definida com uma plataforma capaz de receber sinais de áudio, vídeo e dados, utilizando sinais de radiodifusão nas faixas de frequências de $470 \mathrm{MHz}$ a 806 $\mathrm{MHz}$ (UHF), no Brasil. Este sistema permite a recepção de imagens em alta definição, com som de alta qualidade e em breve visa permitir a implantação da interatividade com o usuário e outros serviços.

Com a mudança da faixa de frequência de transmissão dos sinais da TV analógica para TV digital de alta definição, pesquisadores realizam estudos em relação a melhores estruturas utilizadas para aumento do nível de sinais digitais.

Assim, este trabalho apresenta o desenvolvimento de um amplificador de radiofrequência fundamentando em um

Este trabalho teve suporte financeiro da empresa W3Sat através do projeto de pesquisa intitulado desenvolvimento de antenas para recepção de sinais digitais em televisores de alta definição (HDTV).

D. D. Moura, Universidade Federal de Santa Catarina (UFSC), Florianópolis, Santa Catarina, Brasil, diegodemouraa@gmail.com

I. C. Cezário, Universidade Federal de Santa Catarina (UFSC), Florianópolis, Santa Catarina, Brasil, cezario@gmail.com

A. Raizer, Universidade Federal de Santa Catarina (UFSC), Florianópolis, Santa Catarina, Brasil, raizer@eel.ufsc.br transistor de alta frequência. No intento de obter o sinal digital a ser amplificado, uma antena dipolo de meia onda $(\lambda / 2)$ com geometria inspirada na antena do tipo meander line antena (MLA) também é desenvolvida. Além disso, simulações dos diagramas de diretividade 2D da antena são realizadas.

Par verificar o aumento do nível dos sinais digitais de alta definição recebidos através da antena, medidas foram realizadas utilizando equipamento especifico para tal.

\section{Desenvolvimento do AmplificAdor DE RADIOFREQUÊNCIA}

Com o propósito de realizar o aumento dos níveis dos sinais digitais de alta definição, o circuito eletrônico ilustrado na fig. 1 foi desenvolvido. O circuito é um amplificador de banda larga que amplifica sinais na faixa de frequência de $40 \mathrm{a}$ $900 \mathrm{MHz}$, incluindo assim, a faixa de operação da HDTV (470 $\mathrm{MHz}$ a $806 \mathrm{MHz}$ ).

Além disso, o circuito opera com tensão de alimentação de $9 \mathrm{~V}$, tem impedância de entrada e saída igual a $75 \Omega$. Este valor de impedância foi utilizado, para se obter a máxima transferência de potência, pois as impedâncias da antena e do receptor do televisor ambas apresentam este valor.

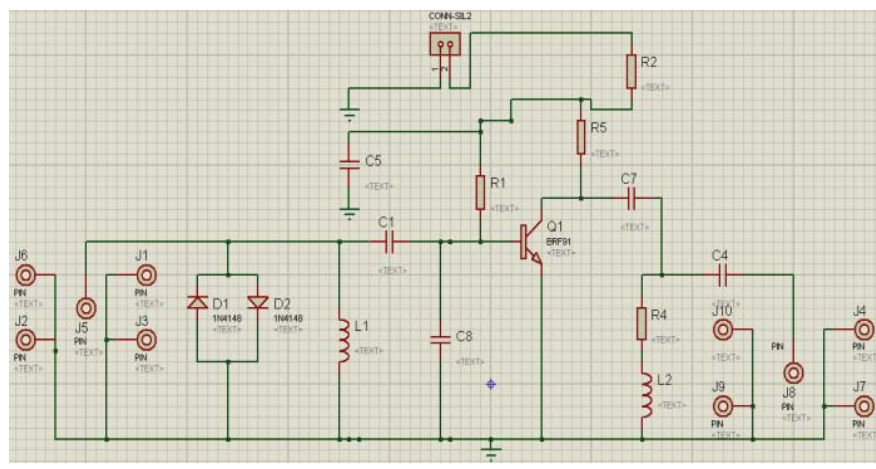

Fig.1 - Circuito elétrico do amplificador de RF.

$\mathrm{O}$ circuito amplificador tem como elemento principal o transistor BFR 91, ilustrado na fig. 2. Este componente é um semicondutor NPN, com encapsulamento tipo Macro T, constituindo ainda por três terminais: (1) coletor, (2) emissor e (3) base respectivamente. Sua faixa de amplificação se estende até a frequência de $1.6 \mathrm{GHz}$, com ganho aproximado de até 23 
dB. Onde, a amplificação do sinal é realizada através do sinal oriundo da antena, que é aplicado na entrada do circuito através da base do transistor. Posteriormente o sinal amplificado é extraído no coletor e conduzido a entrada do receptor da HDTV.
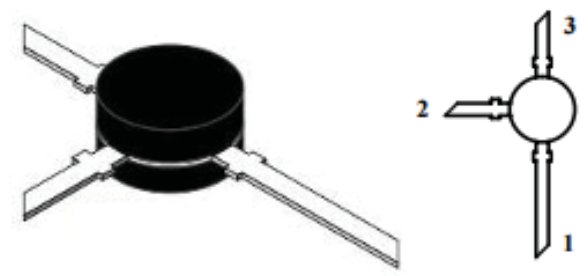

Fig. 2 - Transistor BRF 91

\section{DesenVolvimento DE ANTENA}

\section{A. Fundamentação do Dipolo de meia onda $(\lambda / 2)$}

Para o desenvolvimento da antena utilizada como referência para amplificação dos sinais digitais de recepção da HDTV, foi utilizada uma das topologias mais comuns, o dipolo de meia onda $(\lambda / 2)$. Esta configuração é constituída por dois condutores com uma alimentação central, onde a distribuição dos campos eletromagnéticos é gerada pela diferença de potencial entre os dois elementos constituintes da antena [1], como ilustra a fig. 3 .

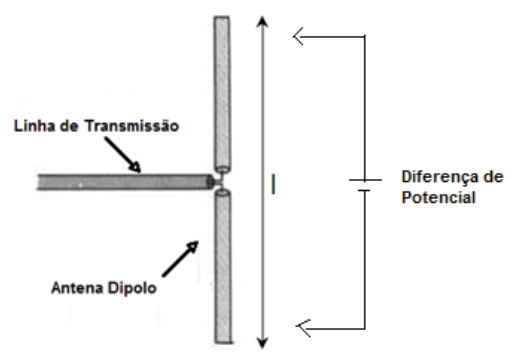

Fig. 3 - Dipolo de meia onda $(\lambda / 2)$

De acordo com [1] os campos distantes de uma antena linear fina, de comprimento 1, simétrica e alimentada pelo centro, pode ser determinado por:

$$
E_{\theta}=\eta_{\theta} \frac{I_{0}}{2 \pi r}\left[\frac{\cos \left(\frac{\beta l}{2} \cos \theta\right)-\cos \left(\frac{\beta l}{2}\right)}{\sin \theta}\right] j e^{-j \beta r}
$$

Na região de campos distantes $H_{\phi}=E_{\theta} / \eta_{0}$

$$
H_{\phi}=\frac{I_{0}}{2 \pi r}\left[\frac{\cos \left(\frac{\beta l}{2} \cos \theta\right)-\cos \left(\frac{\beta l}{2}\right)}{\sin \theta}\right] j e^{-j \beta r}
$$

As equações (1) e (2) permitem calcular os campos radiados $E_{\theta}$ e $H_{\phi}$ por uma antena dipolo, onde a forma do diagrama de campo é dada pelo fator entre colchetes. Assim, através da fig.4 é possível visualizar o diagrama de campo para antena dipolo de meia onda.

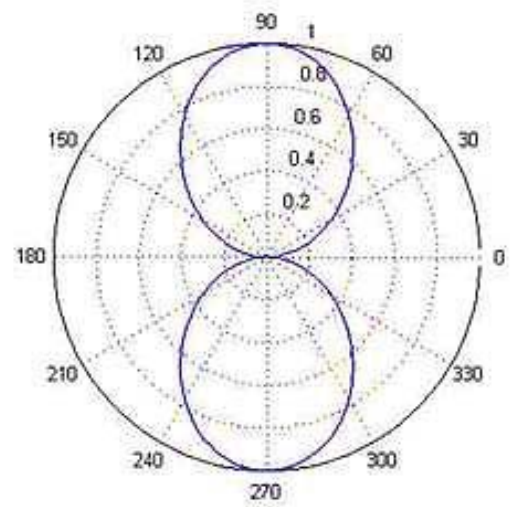

Fig. 4 - Diagrama de radiação do dipolo de meia onda ( $(\lambda / 2)$.

O diagrama ilustrado acima mostra como um dipolo deve comportar-se idealmente. Onde temos em azul os lóbulos superiores e inferiores, que demostram a máxima diretividade da antena. Além disso, é possível visualizar por meio do gráfico, que o ângulo em relação ao eixo y sugere a presença de modos superiores.

\section{B. Desenvolvimento da Antena}

Baseado na teoria exposta, e considerando a seguinte equação:

$$
d=\frac{\lambda}{2}
$$

onde $d=$ comprimento da antena,

os seguintes limites dimensionais $(19 \mathrm{~cm} \leq \mathrm{d} \leq 32 \mathrm{~cm})$ foram obtidos para as frequências limites de operação da HDTV (806 $\mathrm{MHz}$ e $470 \mathrm{MHz})$.

No entanto, com o intento de melhorar o desempenho da antena, a geometria desta foi baseada na antena meander line, conforme é possível observar na fig. 5. Este tipo de topologia vem sendo muito utilizada pois auxilia na redução do comprimento da antena [2], [3]. Sendo que, a redução dimensional é obtida porque a estrutura é constituída por um conjunto de arrays retangulares, possibilitando assim, a redução da frequência de ressonância e o aumento da resistência de radiação em relação a um dipolo convencional.

Para realizar o cálculo das dimensões desta estrutura foi utilizada a teoria apresentada em [1].

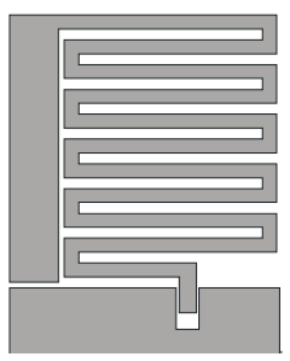

Fig. 5 - Antena Meander Line(MLA) 
Com isso, as dimensões obtidas são aquelas ilustradas na Fig. 6. Como é possível observar, a antena possui $202 \mathrm{~mm}$ de comprimento por $35 \mathrm{~mm}$ de largura e foi fabricada em aço inox.
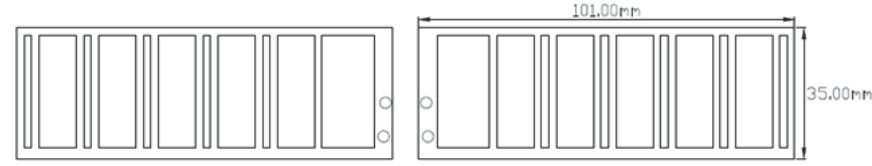

Fig. 6 - Antena dipolo desenvolvida

\section{Modelagem e Simulações NumÉRICAS}

\section{A. Modelagem Por Elementos Finitos}

Com o objetivo de realizar a modelagem da antena, foi utilizado o software fundamentado no método dos elementos finitos [4]. Como é possível visualizar através da fig. 7, a antena foi modelada com as características físicas e geométricas de acordo com o desenvolvimento descrito anteriormente.

Além disso, para modelar as condições de contorno, foi inserido no entorno do dispositivo uma caixa de ar com permissividade e permeabilidade relativa igual 1,0006 e 1 respectivamente.

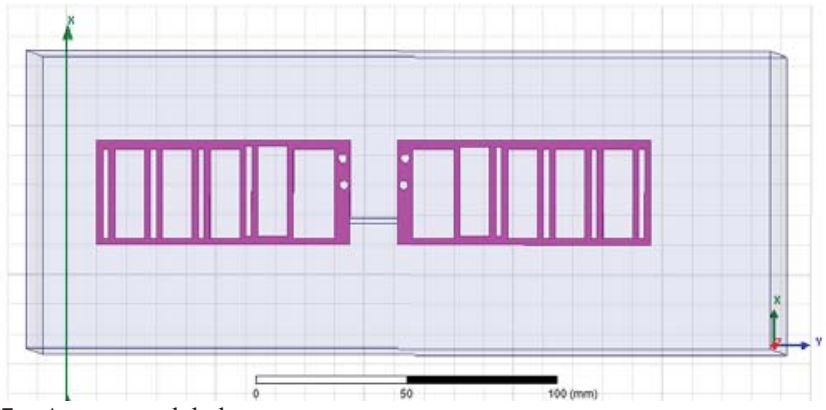

Fig. 7 - Antena modelada

\section{B. Simulação do Diagrama de Diretividade}

Após a modelagem da antena, simulações dos diagramas de diretividade (2D) foram realizadas para as frequências de 470 $\mathrm{MHz}$ e $806 \mathrm{MHz}$, como é possível visualizar através da figs. 8 e 9 .

A partir da análise dos diagramas de radiação apresentados, é possível verificar através dos lóbulos em vermelho $\left(\phi=0^{0}\right)$ e roxo $\left(\phi=90^{\circ}\right)$ que no plano $\mathrm{y}=0$ a antena desenvolvida apresenta máxima diretividade, e a angulação em relação ao eixo y indica a presença de modos superiores.

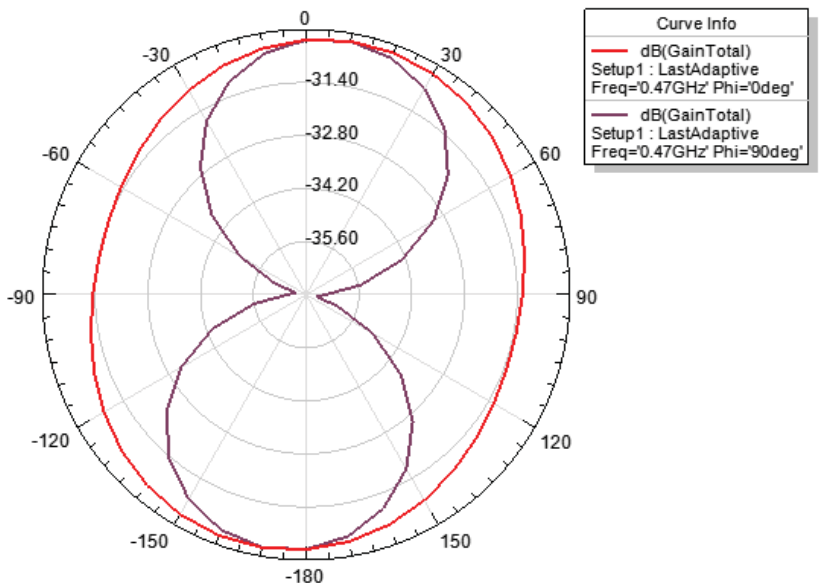

Fig. 8 - Diagrama de diretividade da antena para frequência de $470 \mathrm{MHz} \varphi$ $=0^{\circ}$ e $\varphi=90^{\circ}$

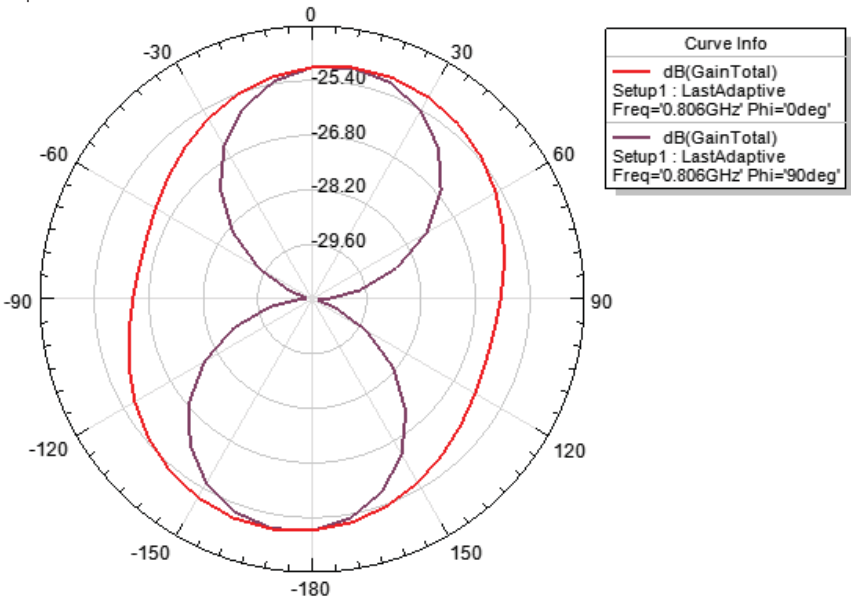

Fig. 9 - Diagrama de diretividade da antena para frequência de $806 \mathrm{MHz} \varphi$ $=0^{\circ}$ e $\varphi=90^{\circ}$

Ao realizar o comparativo com o diagrama teórico apresentado na fig. 4, é possível observar que a antena desenvolvida está funcionando de acordo as características deste tipo de estrutura.

\section{MEDIDAS}

Com o objetivo de avaliar a recepção dos sinais da antena, medidas foram realizadas utilizando o analisador de espectro FSH3 fabricado pela empresa Rohde \& Schwarz. Este equipamento permite realizar análise dos sinais oriundos das transmissoras de sinais. Ou seja, os sinais digitais dos canais abertos advindos das transmissoras são captados pela antena, e posteriormente a leitura das frequências $(\mathrm{MHz})$ e amplitudes $(\mathrm{dBuV})$ dos canais é realizada no equipamento dentro da faixa de operação da TV digital (470 MHZ a 806MHz).

Medidas foram realizadas através do FSH3 para todos os canais digitais abertos disponibilizados: TV Brasil, Rede Globo, Rede Record, SBT, Rede Bandeirantes, Rede TV, Record News, TV Senado e TV Câmara, como ilustrado na tabela I. 
Tabela I - Canais digitais abertos

\begin{tabular}{c|c}
\hline \multicolumn{1}{l|}{ Canal } & $\begin{array}{c}\text { Frequência } \\
(\mathrm{MHz})\end{array}$ \\
\hline TV Brasil & 479143 \\
\hline Rede Globo & 515143 \\
\hline Rede Record & 527143 \\
\hline SBT & 533143 \\
\hline Band & 545143 \\
\hline Rede TV & 557143 \\
\hline Record News & 662143 \\
\hline TV Senado & 689143 \\
\hline TV Câmara & 755143
\end{tabular}

Através da análise da Fig. 9, é possível verificar os valores das amplitudes dos seguintes canais digitais abertos: TV Brasil (46 dBuV), Rede Globo (38 dBuV), Record (38 dBuV), SBT (46 dBuV), Band (42 dBuV), Rede TV (38 dBuV), Record News (38 dBuV), TV Senado (34 dBuV), TV Câmara (35 $\mathrm{dBuV})$. Desta forma, a recepção da antena dipolo mostrou-se satisfatória em relação a recepção dos canais digitais abertos disponibilizados na região, pois todos os canais apresentaram valores superiores ao valor mínimo proposto pela norma nacional (32 dBuV) [5].

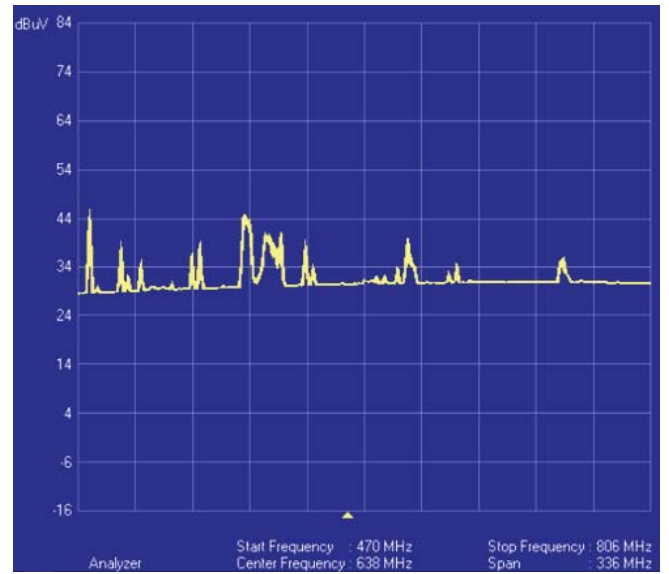

Fig. 9 - Medida dos canais digitais abertos.

A fim de verificar o aumento do nível dos sinais digitais obtidos no receptor do televisor de alta definição, a mesma foi conectada na entrada do amplificador via cabo coaxial. A saída do circuito foi conectada a entrada do televisor também via cabo coaxial, como ilustra a fig.10. Desta forma, medidas foram realizadas para os canais digitais abertos utilizando o osciloscópio DPO 5024.

Como é possível visualizar através da fig.11, medidas foram realizadas para o canal TV Brasil (479.143 MHz), onde foi obtido o valor amplitude de $210 \mathrm{mV}$ para o sinal de entrada (sinal na antena) e $394 \mathrm{mV}$ para o sinal de saída (sinal na entrada do televisor).

Posteriormente, utilizando o mesmo setup, medidas do nível de sinal na entrada e saída foram realizadas para todos os canais digitais abertos. Desta forma, como é possível observar na tabela II, com a utilização do amplificador, os níveis dos sinais digitais disponíveis na entrada do televisor têm um aumento significativo. Ou seja, foi possível obter ganhos em relação aos sinais oriundos da antena (sinal de entrada) e os sinais recebidos na entrada do receptor da TV (sinal de saída) que variaram de 1,87 até 5. Logo, a utilização do sistema amplificado proposto, pode ser uma boa opção para localidades que apresentam baixos níveis de recepção dos sinais digitais.

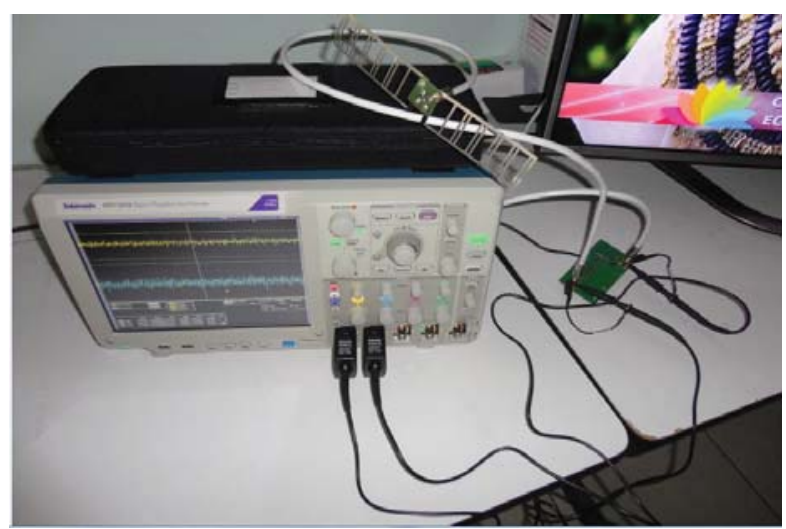

Fig. 10 - Circuito amplificador conectado entre HDTV e antena.

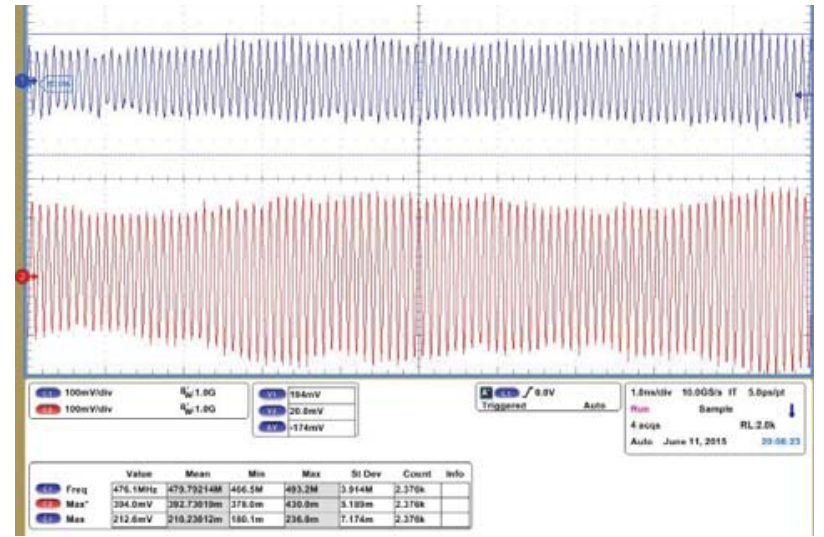

Fig. 11 - Medidas no osciloscópio do sinal amplificado (TV Brasil).

Tabela II - Medidas do aumento dos sinais digitais.

\begin{tabular}{c|c|c|c}
\hline Canal & $\begin{array}{c}\text { Frequência } \\
(\mathrm{MHz})\end{array}$ & $\begin{array}{c}\text { Sinal de } \\
\text { Entrada } \\
(\mathrm{mV})\end{array}$ & $\begin{array}{c}\text { Sinal de Saída } \\
(\mathrm{mV})\end{array}$ \\
\hline TV Brasil & 479143 & 210 & 394 \\
\hline Rede Globo & 515143 & 78.95 & 197.45 \\
\hline Rede Record & 527143 & 78.95 & 197.45 \\
\hline SBT & 533143 & 199.2 & 498 \\
\hline Band & 545143 & 125.7 & 314.25 \\
\hline Rede TV & 557143 & 78.98 & 263,26 \\
\hline Record News & 662143 & 78.98 & 194.45 \\
\hline TV Senado & 689143 & 50.05 & 126 \\
\hline TV Câmara & 755143 & 55.09 & 275.45 \\
\hline
\end{tabular}




\section{CONCLUSÃO}

Neste artigo foi desenvolvido um amplificador de radiofrequência utilizado para o aumento do nível dos sinais digitais utilizados em televisores de alta definição. Além disso, uma antena dipolo de meia onda $(\lambda / 2)$ com a estrutura fundamentada na geometria meander line antenna também foi desenvolvida.

Através das simulações e medidas realizadas para antena, é possível dizer que a estrutura apresentou resultados satisfatórios em relação à recepção dos sinais digitas. Além disso, através do desenvolvimento do amplificador, um aumento dos níveis dos sinais digitais foi alcançado.

Desta forma, torna-se evidente que o sistema amplificado proposto, pode trazer contribuições em relação à recepção dos sinais digitais, sobretudo para localidades onde o nível dos sinais possuem valores reduzidos em suas amplitudes.

Assim, estudos relacionados ao aumento dos níveis dos sinais digitais de alta definição, devem ganhar importância nos tempos atuais, especialmente com a iminente extinção dos sinais analógicos.

\section{REFERÊNCIAS}

[1] C. A. BALANIS, Antena theory-analysis and design, 3 ed., New York: John Wiley \& Sons, Volume 2, 2005.

[2] K. W CHEN, C. L. YANG , A Method for Input Impendence Matching of PIFA based on Meander Line Antenna, International Symposium on Antennas and Propagation (ISAP), 2- 5 December, 2014.

[3] D. MISMAN, M.N. HUSAIN; M.Z.A ABD AZIZ,., I.A. KADIR, M.F.A. SALAMAT, M.R.C. ROSE; M. SHAH; P.J. SOH, The Study of a Different Impedance Meander Line for Microstrip Antenna Design, 6th National Conference on Telecommunication Technologies 2008 and 2008 2nd Malaysia Conference on Photonics. NCTT-MCP, 26-28 August, 2008.

[4] (2014). ANSYS HFSS website. [Online]. Available: http://www.ansys.com/Products/Simulation+Technology/Electronics/Sig nal+Integrity/ANSYS+HFSS

[5] Norma ABNT NBR15604:2007, Televisão digital terrestre Receptores.

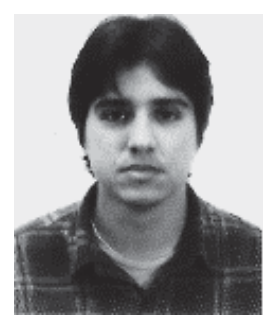

Diego de Moura, nasceu em Chapecó, Santa Catarina, Brasil, em 1982. Recebeu o diploma em Sistemas Eletrônicos pelo Instituto Federal de Santa Catarina, em 2007, e o título de mestre em engenharia elétrica pela Universidade Federal de Santa Catarina, em 2011. Atualmente é doutorando em engenharia elétrica e membro do Grupo de Engenharia de Compatibilidade Eletromagnética da Universidade Federal de Santa Catarina. Suas áreas de interesse são campos eletromagnéticos, compatibilidade eletromagnética e modelagem eletromagnética de sistemas eletrônicos.

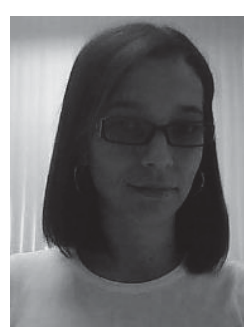

Ingrid C. Cezário nasceu em Nova Trento, Santa Catarina, Brasil, em 10 de agosto de 1983. Recebeu o diploma em Sistemas Eletrônicos pelo Instituto Federal de Santa Catarina, em 2008, e o título de mestre em engenharia elétrica pela Universidade Federal de Santa Catarina, em 2012. Atualmente é doutoranda em engenharia elétrica e membro do Grupo de

Engenharia de Compatibilidade Eletromagnética da Universidade Federal de Santa Catarina. Suas áreas de interesse são campos eletromagnéticos, compatibilidade eletromagnética e modelagem eletromagnética de sistemas eletrônicos.

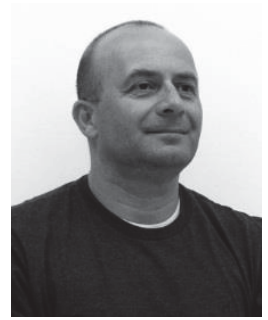

Adroaldo Raizer, nasceu em Lages, Santa Catarina, Brasil, em 11 de agosto de 1963. Recebeu os títulos de engenheiro eletricista (1985) e mestre em engenharia elétrica (1987), ambos pela Universidade Federal de Santa Catarina. Em (1991) concluiu o doutorado em engenharia elétrica pelo Institut National Polytechnique de Grenoble, França. Atualmente Dr. Raizer é professor titular do Departamento de Engenharia Elétrica e Eletrônica da Universidade Federal de Santa Catarina. Atua também como coordenador do Grupo de Engenharia e Compatibilidade Eletromagnética (GEMCO) e do Laboratório de Eletromagnetismo e Compatibilidade Eletromagnética (Maglab). Suas áreas de interesse são campos eletromagnéticos, compatibilidade eletromagnética e métodos numéricos.

Cite this article:

de Moura, D., C. Cezário,I., Raizer, A.; 2015. Desenvolvimento de Sistema de Recepção com Amplificação do Nível de Sinal Digital de Alta Definição. SET EXPO PROCEEDINGS. ISSN Print: 2447-0481.ISSN Online: 2447-049X. v.1.doi: 10.18580/setep.2015.1.13 Web-link: http:/ dx.doi.org/10.18580/setep.2015.1.13 